\title{
Sex therapists make their voices heard
}

\author{
Susan Quilliam
}

Freelance Writer, Broadcaster and Agony Aunt, Cambridge, UK

\section{Correspondence to}

Ms Susan Quilliam;

susan@susanquilliam.com

Received 4 May 2012

Accepted 15 May 2012

\section{Background}

As regular readers of the Journal know, my essential brief for the last decade has been to give voice to my opinion as strongly and stroppily as possible. In this issue, however, I'm stepping back. For my latest commission was to explore the topic of therapy in sexual health not by shouting from my own soapbox, but by allowing others' voices to be heard. To which end, in late 2011, I sent out a call to several psychosexual therapy (PST) organisations asking for respondents to a short survey.

Forty-two psychosexual practitioners answered the call. Respondents came from two main sources: those who had trained initially in counselling itself and those who had trained initially in medicine. Within these two broad streams, there were a range of original backgrounds, with respondents having worked in fields as disparate as general practice, academia, nursing, education, family planning, clinical psychology and genitourinary medicine. There was a range of lengths of service. There was a range of therapeutic approaches. (There were also several well-known names hiding under my guaranteed cloak of anonymity.) To a man - or rather, to a woman, the gender balance being 38-4 to the X chromosome - they answered openly, honestly and at length. Their responses totalled the size of a small book.

\section{Original motivation}

The first question which fascinated me was why my respondents had originally been drawn to working in the psychosexual field. Some motivations were rooted in practicality, a wish to fill a perceived gap in services: “there wasn't anywhere for [patients] to go without paying huge sums of money ... we had difficulty in recruiting clinicians trained in PST ... there was a shortage of support". Other motives were to do with professional competence: "It was a natural progression of my development as a counsellor”, or (perceived) professional incompetence: "Women were asking me questions I hadn't a clue how to answer!"

Some respondents, most movingly, confided personal motivations: "my husband had accused me of being frigid ... I had just come out of a marriage where PE had poisoned the relationship ... my mother was sexually abused ... aged 28 , I realised how wonderful and good sex could be and wanted other couples to achieve that".

The common and unifying thread throughout every answer, however, was simple: respondents had moved into psychosexual work because their patients needed it. Patients such as pre- and postbirth women; men with erectile dysfunction; women who had suffered female circumcision, rape, abuse; patients with delayed ejaculation, anorgasmia, pelvic pain, vaginismus; patients unable to consummate their relationship; patients with medical conditions that impacted on their sex lives; patients who although ageing still wanted a full and joyful sex life.

Or to choose perhaps the most stark anecdote, patients such as the widow who, when called in for a smear, proved to still be a virgin. Her clinician wrote: "I remember her feelings of hopelessness, inadequacy, grief. I knew that if I was to be able to help people like her I needed some training. Soon after, I began [studying] psychosexual medicine $\ldots$ a training that has meant more to me than any other".

\section{Training}

Which brings us neatly to my next question: What training had respondents undertaken, and what challenges and rewards did that deliver? The courses mentioned varied: part-time, evening, postgraduate, diploma, and so on. Naturally, there was a large contingent who had taken the training offered by the organisations who had sent out the mailshots, though many respondents had also followed different courses altogether.

What was very clear was that these training pathways were never effortless, never a long weekend with a piece of paper at 
the end. Long hours spent studying, hundreds of hours spent practising. "The amount of work involved in reading round and fulfilling the assignments is huge ... you need a real range of knowledge, skills, physiological and medical background but also a context of cultural, sociological, historical and political awareness". Added one respondent: "I trained as both a doctor and a sex therapist and found the trainings equally demanding".

It wasn't just the intellectual challenge that demanded effort. Most respondents reported some degree of personal challenge, particularly when their own sexual attitudes were challenged by those of their clients; when learning to talk about almost anything in an unembarrassed fashion; or when "dealing with jaw-dropping moments constructively and respectfully rather than just pretending to be cool!"

As mentioned previously, different respondents came from different initial backgrounds, and these understandably brought their own challenges. Those with a counselling background often admitted to finding the science and the medical content sometimes difficult: "The first thing I did was to buy a book of anatomy and a medical dictionary, then try to catch up!" While the clinicians needed to "remember that in psychosexual work I am not the expert" ... to "let go of the doctor's paternalistic attitudes ..." and to "tolerate not knowing, not having the answers".

All that said, almost every respondent spoke positively of their training as having not only fulfilled their original motivations, but having delivered huge development both professionally and personally. "A huge boost in awareness and knowledge ... increased confidence ... decreased embarrassment ... a widening of my own boundaries...", "I come from an age when medicine was taught via ritual humiliation, so was amazed and delighted by the process of the PST training".

\section{Challenges}

Training over, what is the respondents' experience of working in the field? Perhaps the strongest message that came through the survey answers was a hugely optimistic one. PST actually works. Clients do make changes. They do see results. They are able to gain erections, experience orgasms, regain desire, overcome trauma, have penetrative sex where previously they couldn't. They do come in "fighting one week but holding hands the next", and they do "come in after their first enjoyable sex session with happiness written all over their faces".

But as with training, the therapy journey is not always easy - for the therapist perhaps almost as much as the client. Crucially, my respondents felt a huge sense of responsibility to deliver a result, particularly as clients often arrive having tried numerous other approaches and saying that "if the therapy doesn't work it will be the end of our relationship".
In trying to deliver that result the challenges mount up. Needing to have, and keep up to date with, a wide range of knowledge. Maintaining a neutral and nonjudgmental stance in the face of client confessions. Accurately reading all the clients' communications, verbal and non-verbal. Staying positive and mentally flexible even when working with heartrending situations and vitriolic interpersonal dynamics, for example, "she found him watching porn and made him physically destroy the computer".

Added to which, sometimes client and counsellor do not sing from the same song sheet. Some "fail to attend", others "hope for a quick fix" yet others "resist the tasks" or "savage the counsellor", as one respondent recounted: "I tried to help her see her vagina as an organ of pleasure by likening it to her mouth, enjoying food. I had not recognised the strength of her disgust she complained about me to the authorities".

And all this in the context from outside pressures both within the therapy practice - "I was expected to work with 10 patients a day, 45 minutes each" - and outside it - "We are constantly fighting for funding and recognition ... we are not valued by the health service ... we work in isolation ... professionals in my area have a very low opinion of the effectiveness of our work".

\section{Magic moments}

But let us not get downhearted. When asked about the rewards - what I called the 'magic moments' - of psychosexual work, respondents had a flurry of examples. Tellingly, all the many patient problems I listed out above - from unconsummated relationships through to genital mutilation - were also matched by stories of success. "I was working with an 87-year-old woman whose children thought it disgusting she should still feel desire, but she had a male friend and wanted to have sex." "A young woman came to me for help following an operation to reverse female circumcision but still unable to have intercourse. After a few sessions she was delighted to have succeeded and came back to tell me. 'I knew you'd help', she said, 'You also helped my sister'.”

Within the session, what was particularly mentioned were 'epiphanies'; those breakthrough realisations when clients gain insight. Perhaps this 'aha' moment means realising that help is available and there is a solution to their problem. Perhaps it means feeling suddenly able to talk to the therapist about issues that have previously been taboo, or being unexpectedly able to embrace sexual preferences as normal and not weird. Perhaps it means couples letting go of the anger and starting to feel compassion for each other's pain. "They can suddenly mature; in one case of a man with erectile difficulties, his partner even said he seemed to be taller!"

At these moments, the therapist needs no thanks from the patient but happily, respondents shared many 
times when thanks, though not needed, was offered. "The very first client I treated for vaginismus came back to tell me that she was having a baby, and I was the only person she'd told so far." "Last Christmas I received a lovely card from some former clients that said 'We haven't reached Nirvana yet, but it is a work in progress'.”

\section{Messages}

The final question I asked survey respondents was, I would argue, the most important of all: What do you want health professionals to know about sex therapists? If previous answers were passionate (and they were) then these responses were doubly so. Whether respondents were from a medical or a counselling background, they spoke with one voice.

Their first message is that sexuality is hugely important. "Other than death, sex and love involve the things that affect and motivate human beings more than anything else." And that therefore when there are sexual problems, this impacts deeply not only on human emotions but also on human well-being. "Sexual issues so often underlie physical or mental ill health ... patients often get anxious and depressed, even suicidal ... sorting such issues really aids recovery."

Their second message is - as I mentioned earlier that PST works. It is neither a trivial approach "we don't just hand out hints and tips", nor is it a suspect one "nothing sexual ever happens in the consulting room ... I'm not a prostitute in disguise". It is, however, effective and - crucially in these straitened times - it is also cost effective. "It often takes just a few words to make a change that will affect a patient's entire life." "We can get results within a few weeks or months, usually in less than twelve sessions." "Therapy prevents needless investigations ... drug therapy ... surgery ... PST makes economic sense." "Our work contributes massively to the health of the nation."

Many responders - including some clinicians - recommended that therapeutic principles should be part of initial training for all doctors and nurses and, in particular, part of the training for all specialists in obstetrics and gynaecology, and genitourinary medicine. "It adds a whole new dimension to medical practice ... it has been invaluable to me ... the skills can be used in most settings ... of all branches of medicine it is maybe the most rewarding ... I have used and benefitted from it throughout my professional life."

But perhaps the strongest message that came through in my survey was this. Psychosexual practitioners whether their background be in clinical or counselling work - want dialogue and involvement with the medical discipline. "Talk to us ... please respect therapists, work with them, share knowledge." In return, practitioners long to contribute. "Allow us to work with you ... we would love to support you ... we want to help ... refer on to us." There is, palpably, a wish to reach out and make connections. Let us hope that, for Journal readers at any rate, the feeling is mutual!

My deep thanks are due to everyone who answered the survey and shared their professional and personal experiences; my only regret is that I had to summarise the contributions to approximately one-tenth of the original length. I wish I could have included everything.

My deep thanks also go to the following organisations for supporting the survey by mailing their members: the College of Sexual and Relationship Therapists (http://www.cosrt.org.uk), the Institute of Psychosexual Medicine (IPM) (http://www.ipm.org.uk), the Porterbrook Clinic (http://www.porterbrookclinic. org.uk) and Relate (http://www.relate.org.uk). All these organisations offer psychosexual therapeutic training, details of which are available on their respective websites: the IPM in particular runs courses specifically targeted at clinicians.

In the October 2012 issue of the Journal, in a follow-up piece to this one, I look at how Journal readers can reassure patients about what sex therapy involves.

Competing interests None.

Provenance and peer review Commissioned; internally peer reviewed. 